\title{
Enhancing teaching and learning for Basic Electrical Engineering course using simulation as a tool
}

\author{
Minal Salunke', Vijayalakshmi M. ${ }^{2}$ \\ KLE Technological University, Hubballi. \\ ${ }^{1}$ minal@bvb.edu, ${ }^{2}$ viju11@bvb.edu
}

\begin{abstract}
One of the common difficulties faced by an entrant of an undergraduate course studying Electrical Engineering is in understanding the fundamentals of Alternating circuits (a.c.). In order to address the identified difficulty, modern engineering tool was introduced to enhance the learning in a.c. circuits as simulation tool plays an important role within the frame of teaching and learning in education across the world. With the performance of students in continuous internal examination (CIE) being less, there was a need to improvise their understanding the concepts of a.c. circuit, hence this activity was planned and implemented. The activity was initiated with the introduction to Personal computer Simulation Program with Integrated Circuit Emphasis (PSPICE) simulation tool. Simulation tool was applied in designing structured learning experiences and it was targeted to enhance teamwork competencies and understand the fundamentals of a.c. circuits. Students were trained to simulate complete and well-formed circuits which helped their learning environment suitable for supplementing traditional method of chalk and talk instruction. The activity was concluded by a feedback survey to measure the effectiveness of learning through simulation assignment on teaching \& learning process in regular curriculum. The response from the students' feedback showed that they were more satisfied with simulation assignment compared to conventional one; it helped them to understand theoretical concepts better. It also showed increased involvement in learning during the activity. The performance in CIE was compared with semester end examination (SEE), and it was found that the students' performance in SEE showed significant improvements in understanding the concepts of a.c. circuits. The work presented in this paper summarizes the effectiveness of simulation package used in enhancing teaching and learning in fundamental course of electrical engineering.
\end{abstract}

Keywords: Simulation, Electrical, Learning, Teaching

\footnotetext{
Minal Salunke ${ }^{1}$

KLE Technological University, Hubballi

${ }^{1}$ minal@bvb.edu
}

\section{A. Literature Review}

In fundamental Electrical Engineering course, a.c. circuit analysis topic is a requirement for electrical engineering technology curricula. Typically, this course has been taught using traditional methods where a set of concepts are presented to the students in the classroom. Different teaching methodologies have been adopted to help students learn the topic better. Kulatunga (1999), for instance, implemented computer-based review sessions to improve students' conceptual understanding of electrical circuits [1]. Starting with the hypothesis that if students participated in interactive review sessions on concepts taught before new concepts were introduced, these students would be more likely to apply what they learned to complex problems more successfully. Reisslein et al. (2005) investigated the impact of text- and pictorial-based instruction prompts in a computer based learning environment created for electrical circuit analysis on learning [2]. Other theoretical and pedagogical methods for circuit analysis courses are abundant in the literature, including using behavioral analysis to increase student confidence, student-designed web-based learning program, multimedia teaching tools, and improving student's life-long learning skills via student-centered teaching and learning [3]. Other techniques of teaching that are applicable to circuit analysis courses include the work by Michael Prince (2005) on cooperative learning in freshmen courses [4]. He studied the literature on active learning. Active Learning refers to "any instructional method that engages the students in the learning process." Prince defines collaborative learning as "any instructional method in which students work together in small groups toward a common goal." Finally, cooperative learning involves "a structured form of group work where students pursue common goals while being assessed individually." Karla A. Smith et al. (2005) [5] focuses on classroom-based pedagogies of engagement, particularly cooperative and problem-based learning. It includes a brief history, theoretical roots, research support, summary of practices, and suggestions for redesigning engineering classes and programs to include more student engagement. Authors also lay out the research ahead for advancing pedagogies aimed at more fully enhancing students' involvement in their learning. R. Pucher et al. 
(2002) [6] tried to deal with the motivation of students. The main motivation of students is - of course - to achieve good test results and only the lesser focus lies on the specific contents of the subject. The authors tried to develop a method, which allows the students to focus their intrinsic motivation onto the study project itself and not onto the extrinsic motivation, namely test results. The proposed work in this paper is the motivation from varied authors who tried to make learning much simpler. An activity was conducted for the entrants of engineering course for the course basic electrical engineering.

\section{B. Methodology}

\section{Problem definition}

To enhance teaching and learning process by introducing a simulation tool to strengthen the fundamental concepts learnt. Dwight and Juan (1997) [7] gave different approach to introduce freshmen students to electrical engineering (EE). The main goals were teaching problem-solving skills, teaching the required knowledge in complex numbers and matrix operations, introducing PSpice and Matlab, starting to develop communication skills, engaging freshmen in group work etc.

Since introductory courses play an important role in student retention and success, there arises a need to generate new ideas to ensure student interest, attention and learning. Many groups studied innovative methods to achieve the desired classroom goals. Instructors are constantly seeking innovative methods to teach students the engineering concepts in fundamental courses. Fundamental courses are particularly important for student retention, since these courses are the students" "first impression" of the engineering department or program. Additionally, the beginner is more excited to explore soft skills and apply fundamental concepts learnt. In this paper, a simulation tool is utilized to enhance the teaching and learning process for the topic a.c. circuits.

\section{Simulation Tool}

Simulation is a technique for practice and learning that can The be applied to many different disciplines. In this activity a student version of PSPICE (Personal Computer Simulation Program for Integrated Circuits Emphasis) which is a general purpose circuit simulator is used to verify circuit designs and to predict the circuit behavior [8]. Circuit design requires accurate methods for evaluating circuit performance. Because of the enormous complexity of modern integrated circuit, computer-aided circuit analysis is essential and can provide information about performance that is almost impossible to obtain with laboratory prototype measurement.

\section{a) The objectives of the activity}

- to comprehend the concepts of a.c. circuits through simulation

- to provide opportunities for students to work and learn in team.

- to review the level of individual involvement in the activity of this course.

\section{b) Conduction of the activity}

- The class strength of 70 was divided into 12 teams. Each group consisted of 5-6 students

- Team was formed on random basis.

- Each team was given 2 sets of a.c. circuit problem.

- Each team had to simulate and verify the circuits using software PSPICE

- Each team had to prepare a report consisting of $\checkmark$ problem statement

$\checkmark$ theoretical calculations

$\checkmark$ simulation results in the form of standard image format

$\checkmark$ comparison table of theoretical and simulated results.

- Each team had to present the outcome work by power point presentation.

c) Role of teacher before and after the activity

Apart from the regular classroom teaching the teacher should use principles of instruction to select or plan and develop activities to best help students learn.

\section{(i) Before}

- Instructed on installation of the software.

- The students were familiarized with the use of PSPICE software

- $\quad$ Emphasis was given on

$\checkmark$ drawing the circuit

$\checkmark$ simulating the circuit

$\checkmark$ analyzing the simulated results

(ii) After

students were evaluated for the activity: The evaluation was based on the ancillary investigation presentations, and on detailed report on work carried out.

\section{d) Sample problem of the activity}

Q. A single phase voltage of $200 \mathrm{~V}$ at $50 \mathrm{~Hz}$ is applied to a circuit comprising of a resistance of $20 \Omega$, inductance of $20 \mathrm{mH}$ and a capacitor of $150 \mu \mathrm{f}$ connected in series. Find (i) impedance of circuit (ii) current drawn from the supply (iii) power factor of the circuit (iv) power drawn from the circuit. Solve the problem theoretically and verify the results by simulating the circuit using student's evaluation software PSPICE.

The simulated results of above problem are depicted in fig.1 below. Table.1 shows the comparison between theoretical and simulated results. Simulations helped the 
students to explore the simulation package and analyze the concepts learnt.

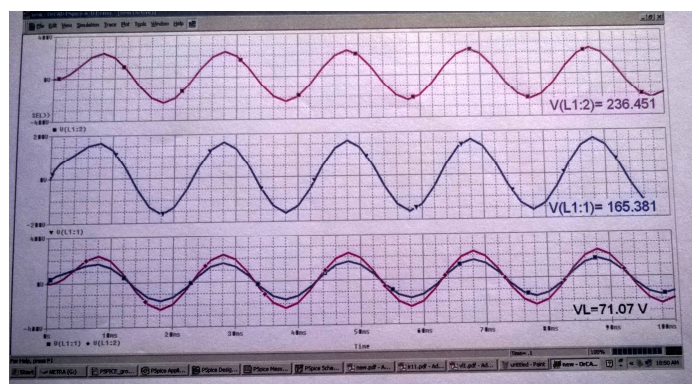

Fig.1 Simulated results

Table 1 Comparison between theoretical and simulated results

\begin{tabular}{|l|c|c|}
\hline \multicolumn{1}{|c|}{ Parameters } & Theoretical & Simulated \\
\hline Supply Voltage $\left(\mathrm{V}_{\max }\right)$ & $282.84 \mathrm{~V}$ & $269.323 \mathrm{~V}$ \\
\hline Supply Current $\left(\mathrm{I}_{\max }\right)$ & $11.33 \mathrm{~A}$ & $11.068 \mathrm{~A}$ \\
\hline $\begin{array}{l}\text { Voltage across } \\
\text { resistor }\left(\mathrm{V}_{\mathrm{R}}\right)\end{array}$ & $226.636 \mathrm{~V}$ & $221.194 \mathrm{~V}$ \\
\hline $\begin{array}{l}\text { Voltage across } \\
\text { Inductor }\left(\mathrm{V}_{\mathrm{L}}\right)\end{array}$ & $71.198 \mathrm{~V}$ & 71.07 \\
\hline $\begin{array}{l}\text { Voltage across } \\
\text { Capacitor }\left(\mathrm{V}_{\mathrm{C}}\right)\end{array}$ & $240.46 \mathrm{~V}$ & $236.451 \mathrm{~V}$ \\
\hline Power factor cos $\varnothing$ & 0.801 lead & 0.799 lead \\
\hline Total Power drawn $\left(\mathrm{P}_{\mathrm{T}}\right)$ & $1.283 \mathrm{~kW}$ & $1.225 \mathrm{~kW}$ \\
\hline
\end{tabular}

\section{e) Assessment}

Assessment was based on the presentation and report submission

Table 2 Assessment Sheet

\begin{tabular}{|l|l|l|l|}
\hline $\begin{array}{l}\text { SL. } \\
\text { No. }\end{array}$ & Name of the Student & USN & Max.Marks: 10 \\
\hline 1 & & & \\
\hline 2 & & & \\
\hline 3 & & & \\
\hline 4 & & & \\
\hline 5 & & & \\
\hline
\end{tabular}

Table 3 Assessment parameters

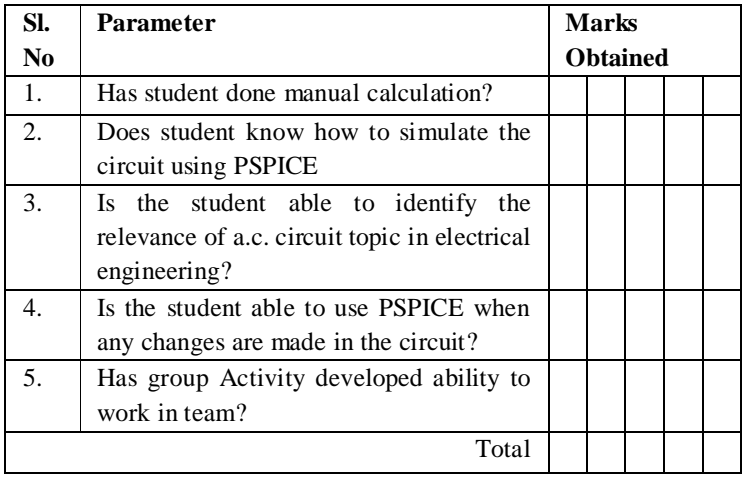

Marks allotted for each question

Answer to Q.No 1 and 2. Yes (1 Mark) No (0 Mark)

\section{Answer to Q.No 3.}

Able to identify all the relevant information (2- 3 Marks)

Identified some but fail to comprehend (1 Marks)

Answer to Q.No 4. Excellent (3 Marks) Good (2 Marks) Moderate (1 Mark)

Answer to Q.No 5. Active participation in team activity (12 Marks) Participated but no contribution (0 Marks).

\section{Results}

To realize the impact of learning happened through simulating the electrical circuits, written examination was conducted and feedback was taken.

The average mark obtained by students on the concepts of a.c. circuit is as tabulated in fig. 2 . It is observed that the performance of the students' was poor on a scale of 10 for higher level questions. In order to improve the overall performance, an activity was designed. It was observed that the performance improved significantly. Fig.3 depicts the improvement on a scale of 10 .

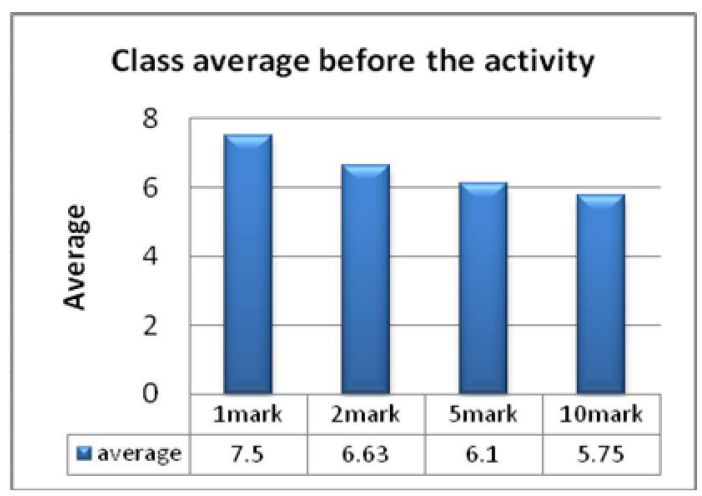

Fig.2. Class average before the activity

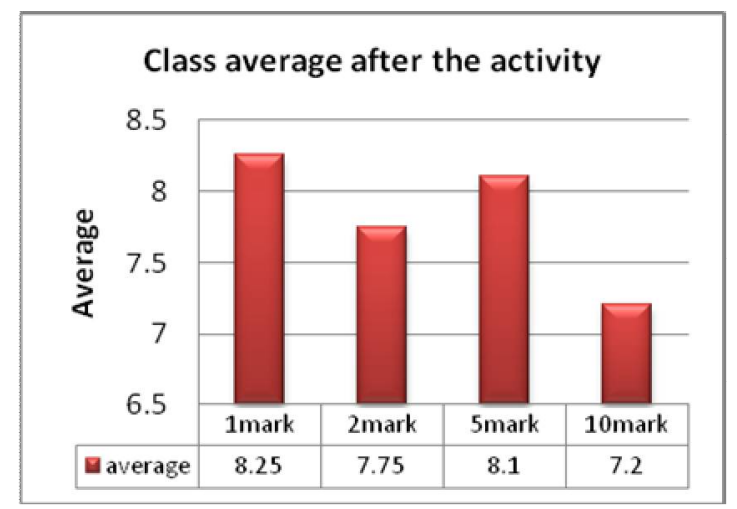

Fig.3. Class average after the activity

\section{Analysis of CIE and SEE}


Table 4 paired t-test on exam results

\begin{tabular}{|l|l|l|l|l|}
\hline \multirow{2}{*}{ Questions } & \multicolumn{2}{|c|}{ Mean } & \multirow{2}{*}{ Stat } & $\begin{array}{c}\mathbf{P}(\mathbf{T}<=\mathbf{t}) \\
\text { one-tail }\end{array}$ \\
\cline { 2 - 3 } & \multicolumn{1}{|c|}{ CIE } & \multicolumn{1}{|c|}{ SEE } & & 0.13 \\
\hline 1 mark & 1.50 & 1.65 & -1.14 & 0.08 \\
\hline 2 mark & 2.65 & 3.10 & -1.48 & 0.08 \\
\hline 5 mark & 3.05 & 4.05 & -2.18 & 0.02 \\
\hline 10 mark & 5.75 & 7.2 & -2.21 & 0.02 \\
\hline
\end{tabular}

A paired t-test was performed to analyze the data obtained from CIE and SEE. From table 4 we can observe that for 1mark, 2 mark, 5 mark and 10 mark questions, there is significant change in mean from CIE to SEE. This means that the difference in mean is statistically significant for these questions. It can be inferred that students were able to attempt even complex questions better after simulating the circuits as their conceptual understanding has improved.

\section{Analysis of Feedback questionnaire}

At the end of activity feedback was taken from the students to identify whether the proposed activity had improved the knowledge or exposure level of a student. Fig.5 below shows the analysis of the feedback. Sample feedback questionnaire is tabulated in Appendix A.

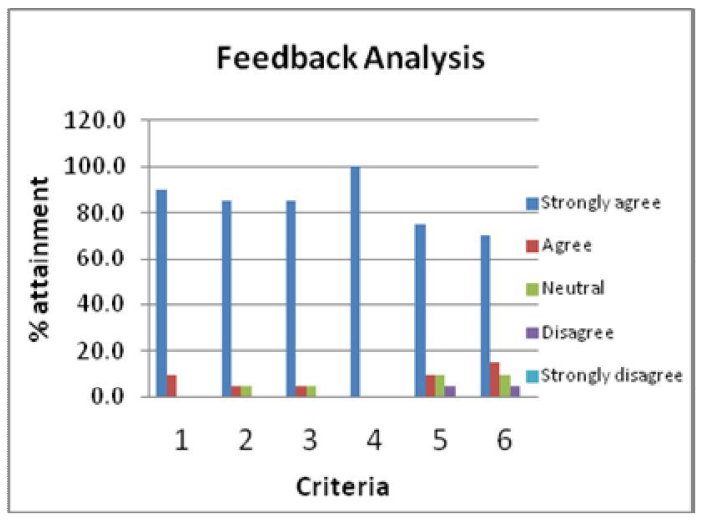

Fig.4. Feedback analysis

It was observed that $90 \%$ students agree on saying simulations helped them understand theoretical concepts. $85 \%$ students strongly agree on practically applying part of the course has helped them enhance their knowledge in general. Adding to the enhancement, $85 \%$ students also strongly agree that simulation as an assignment helped students to prepare better than for any other seminars. The most positive aspect of this activity was $100 \%$ student strongly agree on simulation as an assignment has better value than any other conventional one. $10 \%$ students view was neutral regarding the involvement in this activity. Whereas 5\% students disagreed on spirit of teamwork and cooperation.

\section{CONCLUSION}

In order to go beyond classroom teaching, the activity was conducted to enhance students learning. Examination results show considerable improvement in answering higher level questions. Feedback analysis shows significant learning after the introduction of simulation tool. Students were able to simulate the concepts what is taught in class. Team work helped students in collaborative learning, experiencing new methods to link theory with practical.

\section{REFERENCES}

[1] Kulatunga, A, “Improving Students' Conceptual Understanding of Electrical and Electronics Circuits Via Computer- Based Review Sessions," Journal of Industrial Technology, Vol. 15, No. 2, pp. 1-5, 1999.

[2] Reisslein, J., Atkinson, R. K., Seeling, P. and Reisslein, Martin, 2005, "Investigating the Presentation and Format of Instructional Prompts in an Electrical Circuit Analysis Computer-Based Learning Environment," IEEE Trans. Education, Vol. 48, No. 3, August 2005.

[3] Hudson, T. A., Goldman, M., and Sexton, S. M., 2008, "Using Behavioral Analysis to Improve Student Confidence with Analog Circuits," IEEE Transactions on Education, Vol. 51, No. 3, pp. 370- 377, August 2008.

[4] Michael Prince, "Does Active Learning Work? A Review of the Research," Journal of Engineering Education, pp. 223-231, July 2005.

[5] Karla A. Smith, Sheri D. Sheppard, David W. Johnson, and Roger T. Johnson, "Pedagogies of Engagement: Classroom-Based Practices," Journal of Engineering Education, pp. 87-101, Jan. 2005.

[6] R. Pucher, A Mense and H. Wahi, "How to Motivatge Students in Project Based Learning," 6thIEEE Africon Conference in Africa, Vol. 1, pp 443-446, Oct 2-4, 2002.

[7] Dwight F. Mix and Juan Carlos Balda, "ELEG 1003Introduction to Electrical Engineering: An Approach to Motivate and Teach EE Freshmen," Proceedings of the IEEE Frontiers in Education Conference, Vol. 3, pp. 1215-1218, Pittsburg, Pennsylvania, Nov. 5-8, 1997.

[8] Muhamad Rashid, " Introduction to PSPICE using OrCAD for circuits and Electronics", Third Edition, Pearson Education

\section{APPENDIX A}

Table 5 shows the sample feedback sheet intended to measure the effectiveness of learning through simulation.

Table 5. Feedback Questionnaire 
Dear Students,

This survey is intended to measure the effectiveness of Learning through Simulation assignment on "teaching \& learning" process in regular curriculum. Based on your personal experience, kindly give your valuable feedback by ticking $(\sqrt{ })$ in the relevant box $(\square)$ on Liker five-point scale.

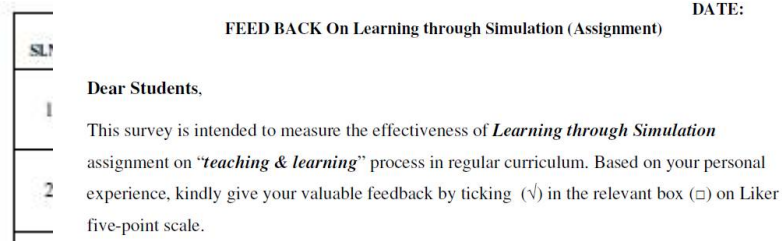

